\title{
Multidisciplinary Studies, Crossreading and Transversal Use of Thermography: The Castle of Monzón (Huesca) as a case study
} Camilla Mileto ${ }^{\text {a }}$, Fernando Vegas ${ }^{\mathbf{b}}$, José Luis Lerma $^{\mathrm{c}}$

Universitat Politècnica de València, Valencia, Spain, ${ }^{\mathrm{a}}$ cami2@ cpa.upv.es, ${ }^{\mathrm{b}}$ fvegas@ cpa.upv.es, ${ }^{\mathrm{c}} \mathrm{jllerma@cgf.upv.es}$

\begin{abstract}
The study carried out at the castle of Monzón (Huesca) while developing the Master Plan for the preservation of the site clearly aims at efficient interaction between different studies by several groups of experts in various disciplines. The various studies were coordinated jointly in order to offer a comprehensive analysis of the monument, intertwining approaches and points of views. Among the techniques used, thermography was especially interesting because of its flexibility and adaptability in several applications: from helping to identify materials to the detection of hidden pathologies. The efficiency of thermography for emphasizing different phenomena can only be improved by combining with other survey and analysis techniques. Synoptic plans allow these techniques to enrich the information available, reaching greater accuracy in determining materials and pathologies.
\end{abstract}

Keywords: Infrared, Interpretation, Inventory, Recording.

\section{Introduction}

This study of the castle of Monzón was devised as part of a Master Plan for the site directed by architects Camilla Mileto and Fernando Vegas and promoted by the Regional Government of Aragon between 2007 and 2009 (Mileto \& Vegas, 2008; Mileto \& Vegas, 2011). The study was developed as a multidisciplinary project focused on thorough knowledge of the monument with a view to defining the main guidelines for conservation-restoration, future uses and management of the castle and surrounding landscape.

This Master Plan was therefore drawn up taking into consideration historical and documentary study (J. Ramón Bosch and J. José Nieto, historians); archaeological study (José Delgado, archaeologist); historical-artistic study (M. Ángel Sorroche and Ana Ruiz, art historians); metric and photometric survey (Sat Survey SRL); constructive and architectural study (C. Mileto and F. Vegas, architects); stratigraphic study of the fabric (C. Mileto and F. Vegas, architects); polemological and hydraulic study (J. Francisco Noguera and Guillermo Guimaraens, architects); geological, petrological and edaphological study (Francisco Martín and Emma Luengo, geologists); diagnosis of material pathologies (Beatriz Martín, restorer and C. Mileto and F. Vegas, architects); structural diagnosis (Adolfo Alonso, Arturo Martínez, Verónica Llopis, architects); thermographic study (J. Luis Lerma and Miriam Cabrelles, engineers); GPR tests (Jorge Padín, engineer); study of cultural management and uses (M. José Viñals, cultural manager); legal and urbanistic study (Javier Peralta and Luisa Salinas, architects); planning and management of the site (César Bargues, economist); photographic documentation of the whole (Tato Baeza, photographer); and direction and coordination of the studies in order to produce the Master Plan guidelines (C. Mileto and F. Vegas, architects). 
Tackling the study of the castle from the different perspectives of each discipline allowed us to compare the data obtained, enriching the different approaches so that the Master Plan could cover and contemplate the complexity of the site. Each part of the project was developed taking other parts into consideration in a continuous exchange of ideas and constant process of mutual enrichment (Mileto \& Vegas, 2008; Mileto \& Vegas, 2011).

\section{The Castle Of Monzón}

The Castle of Monzón (fig. 1), standing for centuries on a promontory, is a point of reference in the territory of the Cinca valley, a milestone in the landscape that is more prominent on the skyline than the town that gives it its name. It is a very compact monolithic element of the landscape. Nevertheless, the fortress that we observe nowadays is enormously heterogeneous, composed of different facings, fabrics, buildings, elements, techniques, materials and states of conservation, derived from the continuous use of the castle over the last millennium.

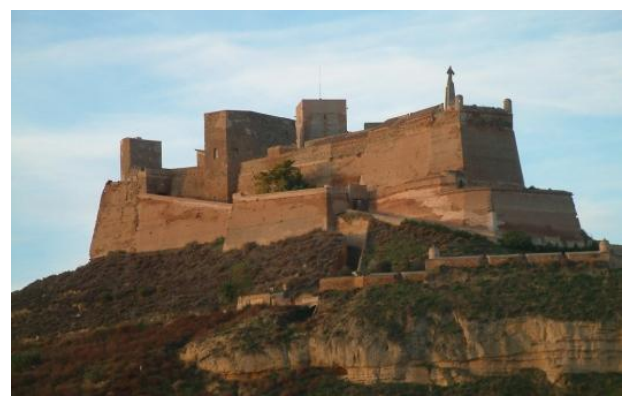

Fig.1 - General view of the castle of Monzón (Huesca) from the north-east

This uninterrupted use during all these centuries translated into the expressive strength that the castle transmits to visitors. Tourist promotion, research and publications on the castle usually emphasize its medieval and Templar character, with all the mythical, tragic, heroic and even esoteric connotations linked to the religious order of the Templars. However, the castle of Monzón represents much more than this part of its history, as its architecture may offer explanations not only of local history, but also of
Spanish history and the evolution of the military defensive systems of castles.

The roots of the castle of Monzón go deep into a hypothetical pre-Roman castle, possibly linked or related to the old Roman villa of Tolus or Tolous. At a later stage, there may have been a Muslim tower or castle (Delgado, 1995) conquered by the Christians in 1089. An important milestone in the history of the castle was its designation in 1143 as headquarters of the Templar castles in the region of Aragon, when it was donated to the Templar order (Castillón Cortada, 1989). From this period, we still conserve the main buildings of the neuroballistic fortress, as well as the traces of its walls. After the extinction of the Order of the Templars in 1317, the castle and the villa of Monzón fell into the hands of the Knights Hospitaller, and again became the centre of this order in the Aragon region (fig. 2). In the 15th century, the castle passed into royal hands and took on a secondary position in the conflicts of the time.

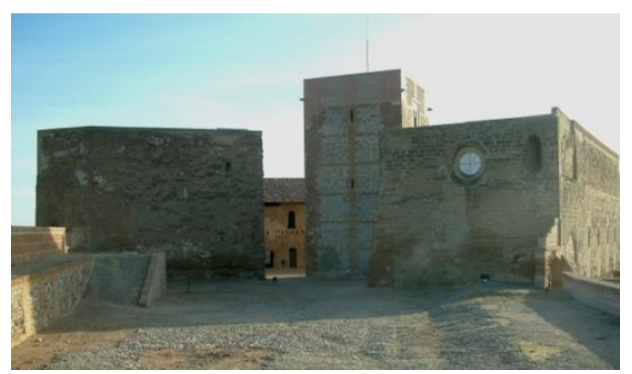

Fig. 2 - Esplanade of the castle with the buildings of the neuroballistic fortress

During the Modern Era, two clearly differentiated periods can be distinguished, that of the reign of the Habsburgs and the later reign of the Bourbons. During this period, the fortress alternated between being a key site in conflicts and being virtually unnoticed. In the 18th century, during the War of the Spanish Succession (1700-1714), the importance of the site was acknowledged and, after the war, work began to adapt the medieval fortress to modern defensive concepts and strategy, radically transforming it in several steps from a neuroballistic into a pyroballistic fortress (Nieto, 2008). 


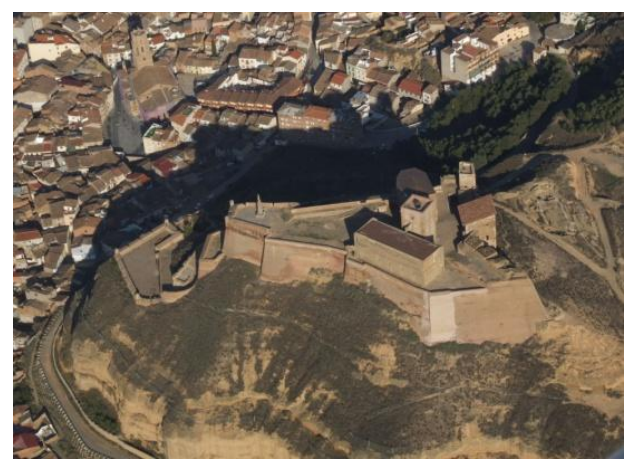

Fig. 3 - South-west aerial view of the castle where the medieval buildings on the upper plateau and the 18th and 19th bastions can be seen

These adaptations continued throughout the $19^{\text {th }}$ century, although these were mainly minor additions, repairs and improvements to the installations. However, following the War of Independence (1808-1814), the castle of Monzón progressively lost its strategic value, although it recovered its importance during the fraught period of 1820-1823, as well as during the four Carlist Wars. After this last episode, the castle of Monzón gradually decayed until 1933, when the Ministry of Defence sold the fortress to the Treasury. In 1949, the castle was classified as a National Monument (fig. 3).

\section{Studies of the castle}

The present situation of the Castle of Monzón and its historic and symbolic importance in the territory have required a strategic Master Plan offering a new step in the understanding of the historic site and its state of conservation, as well as contributing to drafting the guidelines for its future conservation. The areas of study have tackled the different analyses needed in order to obtain an accurate vision of the current situation of the fortress. Thus, several monographic studies were carried out from a historic, morphologic and structural perspective, as well as in terms of decay, relationship with the environment, legal situation and uses, management and diffusion.

Interdisciplinarity ensured analysis and reflections beyond the specific field of each discipline, generating positive synergies, enriching both the study of the castle and the personal and professional experience of the specialists working on the Master Plan.

Several disciplines and techniques have been employed in order to approach the study of the monument (Mileto \& Vegas, 2008; Mileto \& Vegas, 2011) including a metric survey by laserscanner to understand the whole in all its topographical and architectural complexity. These include the existing underground tunnels and mines; petrographical and mineralogical analysis of stone, brick and mortar in order to chemically characterize materials and pathologies; detailed stratigraphical, glyptographical, cronotypological and GPR cross-study of historic documents and artistic elements in order to determine the different constructive phases of the castle; study of water deposits and the hydraulic system in order to understand the pathologies linked to the current water stagnation and infiltration after rainfall, etc. All these studies were done coordinating the different teams, so that the results of individual disciplines benefited the comprehensive understanding of the whole. The interrelation of the studies was implemented not only in the plans and written reports for each chapter, but also in the plans and final written report which allow a transversal crossreading of the characteristics and pathologies of the castle (fig. 4).

Among the techniques employed, thermography deserves special attention because it is transversal and applicable to several objectives. Thermography was used as a non-destructive technique to support the material, pathological and stratigraphic studies. 


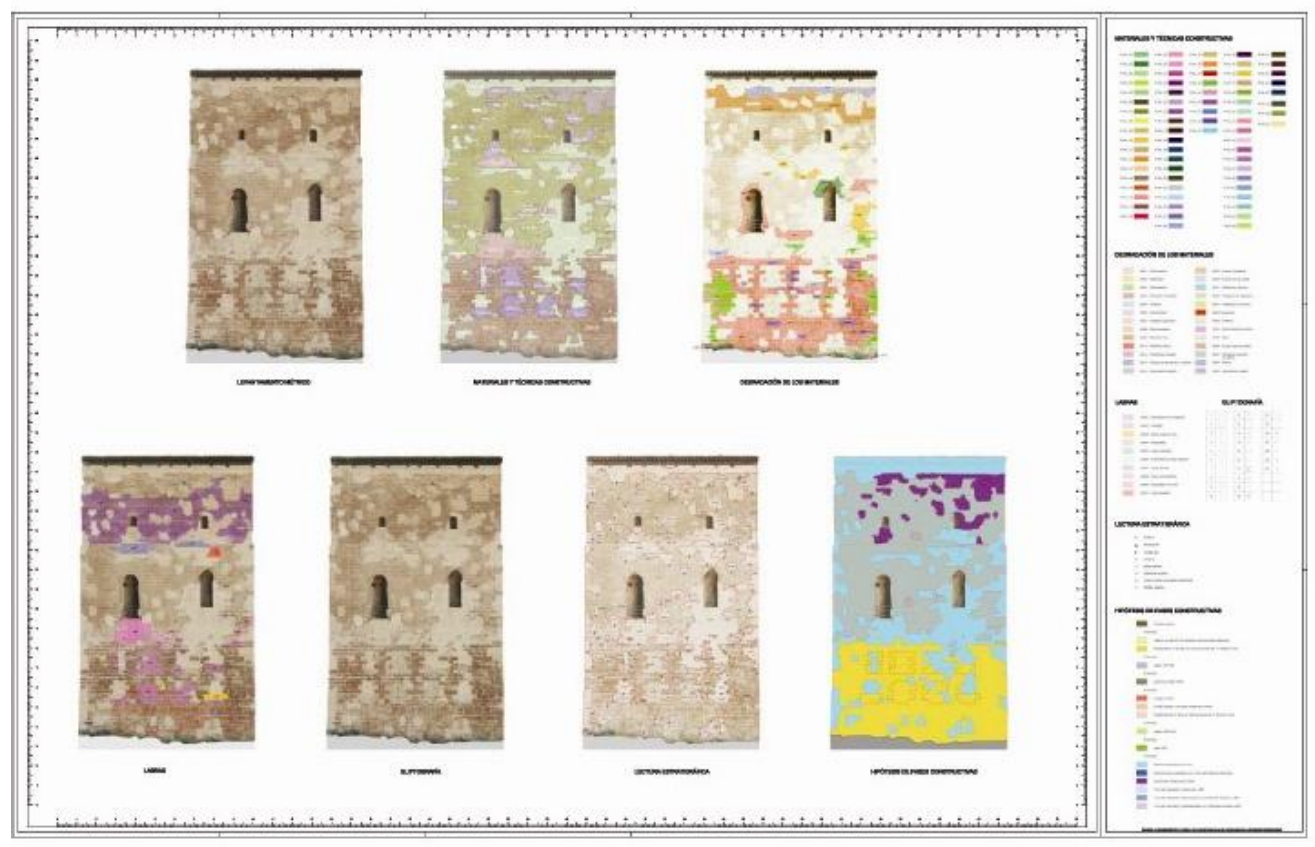

Fig. 4 - Synoptic plan of the various approaches used: photogrammetric survey (a), material study (b), pathologies (c), stonework (d), glyptography (e) and stratigraphy (f and g)

\section{Thermography for architectural cultural heritage applications}

Infrared thermography, also known as thermal imaging, is a technique that records the intensity of radiation in the infrared area of the electromagnetic spectrum. Temperatures are calculated applying the Stephan-Boltzmann law, which relates intensity of radiation and temperature. In addition, infrared radiation is converted by the camera into a visible image. Therefore, the images acquired display information that is not visible to the human eye.

Infrared cameras used for inspection and diagnosis of buildings and monuments work within a range between 8 and $14 \mu \mathrm{m}$. The thermal camera can be used for instance to locate leaks, heating and electrical faults, thermal bridges, termites, mould and badly insulated structures, the visualization of energy losses and, last but not least, moisture content mapping. Besides diagnosis, infrared thermography can also be applied in the evaluation of building materials (Barreira and Freitas, 2007). Therefore, a priori it is an ideal non-destructive testing tool for the survey of both ancient and modern architectural cultural heritage.

Quantitative infrared thermography can be undertaken in constructions following different artificial sources such as air flux or radiant flux (Grinzato et al., 1998). However, qualitative approaches are most widespread given the simplicity of acquiring imagery, and the chance to interpret these after visual inspections (Lerma et al., 2007).

The practice of thermal imaging requires some knowledge and understanding of various principles of heat transfer, thermodynamics and optics (Cañas Guerrero et al., 2005). Some sources affect the accuracy of the output results, including different emissivity values of materials; different behaviour of colour, texture 
and finished materials (bright, smooth or rough); solar irradiance; reflections from surroundings.

\subsection{Data acquisition}

Standalone thermal surveys can be carried out on site. However, for the purposes of cultural heritage documentation, the usual practice consists in combining thermal measurements with additional surveying techniques, such as photogrammetry and laser scanning, or additional visible and multispectral imagery such as ultraviolet and near-infrared (Lerma et al., 2011). The idea is to acquire a comprehensive dataset that allows experts to extract as much accurate information from the remote sensing techniques as possible.

The survey of large complex monuments requires planning in order to take pictures at the right time. However, a study of solar movement is recommended as shadows should be kept to a minimum in the data acquisition process. Generally speaking, areas which are partly shaded and partly under direct irradiation should be avoided.

Depending on the object of the thermographic survey, shots at different times are recommended. Normal surveys have to be carried out either early in the morning, at midday or late in the afternoon. This ensures that all the different effects of the thermal properties of materials, such as specific heat capacity, thermal conductivity, thermal diffusivity and thermal effusivity, can be recorded. The thermal variation of the monument can be analysed, depending on the orientation of the sides where multitemporal thermal surveys are undertaken (Lerma et al., 2011a). When it is also important to monitor thermal stress, pictures should be recorded in different periods, in spring-summer and autumn-winter.

Moreover, outdoor infrared imaging should be carried out with minimum air flow conditions around the surfaces. Indeed, high flow velocities can result in strong cooling effects (Möllmann, et al., 2007).

\subsection{Methodology}

The resolution of thermal cameras tends to be low, while survey areas can be extensive, and resources are for the most part limited. Therefore, thermography has to be integrated into the conventional metric surveys, elevation plans or preferably orthomosaics, although $3 \mathrm{D}$ solutions can be found in the literature (Cabrelles et al., 2009).

One of the simplest approaches makes use of 2D rectification techniques to merge visible and thermal content on planar objects using either conventional image processing software or photogrammetric software. If the object, monument or site is not flat, then orthorectification of the imagery is essential for producing 2D metric drawings. However, current technology allows magnificent 3D models using laser scanning and/or image-based photogrammetric solutions to drape the textural content of the thermal imagery onto the 3D model.

\section{Thermography as a technique to aid transversal analysis}

The final organization of the thermographic documentation allowed us to produce rectified thermophotographs of some of the most outstanding façades within the synoptic plans, aiming to give a global vision of the materials and pathologies of these façades, emphasized and enhanced by the thermographic image (fig. 5). Based on the general observation of the façades it can be stated that thermography allows a clear identification and hence precise positioning of different material densities, as well as porosity, critical moisture content, specific heat capacity and thermal conductivity, and, thus of material decay. 

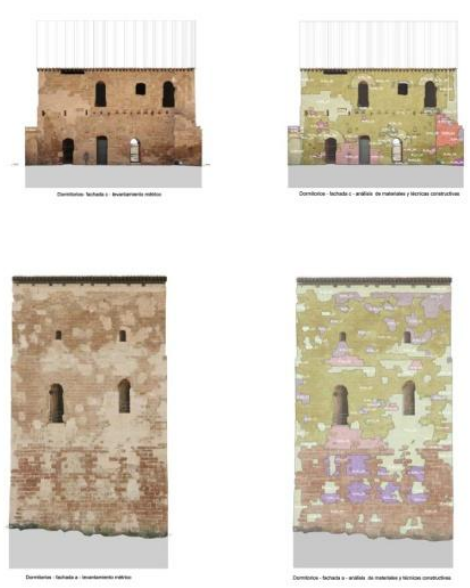
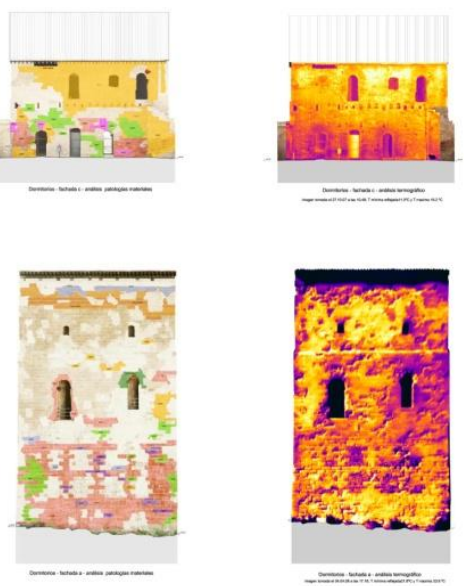

Fig. 5 - Synoptic plans: a) photogrammetric survey; b) material study; c) pathologies; d) thermography

More compact materials appear darker, i.e. colder, while more porous or more disaggregated materials appear lighter, i.e., warmer. Thus, in the rectified thermophotographs ceramic materials stand out more than stone, usually represented in lighter colours. Although this phenomenon is evident in all the façades, it is even more so in the south façade of the Chapel (fig. 6).
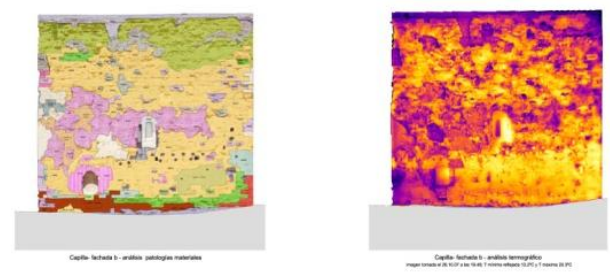

Fig. 6 - South façade of the Chapel where the different materials can be clearly distinguished: Stone in yellow, brick in magenta and purple, and gypsum renderings in orange.

In some cases, the difference in physical and thermal properties between materials, as well as the consequent thermal inertia, allows the ashlars to be clearly distinguished from the mortar joints. The round stones, also denser, always appear much darker than the stone ashlars. This phenomenon is also clearly seen in façades as characteristic as the lower part of the south façade of the Dormitories, the façade of the Donjon tower or the south façade of the Knights' House (fig. 7).

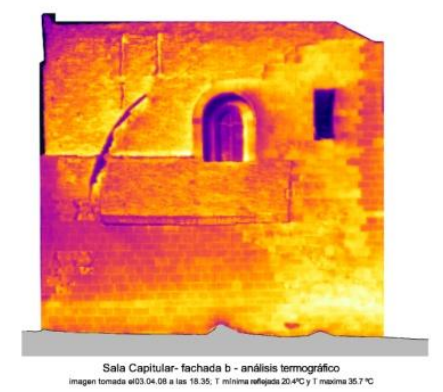

Fig. 7 - South façade of the Knights' House. There is a clear difference between the stone ashlar and the mortar and the different interventions made to date, such as the substitution of the ashlars in the east corner

One interesting phenomenon that thermography is able to emphasize (fig. 8) is the reconstruction of the upper part of the tower with different materials from the original employed in the lower part, a fact which is emphasized by the inverted temperature. In the lower part of the tower, the stone of the ashlars is more porous and therefore warmer than the round stones between the ashlars which are colder. However, in the reconstructed upper part the concrete blocks used and the rendering covering them are warm compared to the angles built with new stone. 

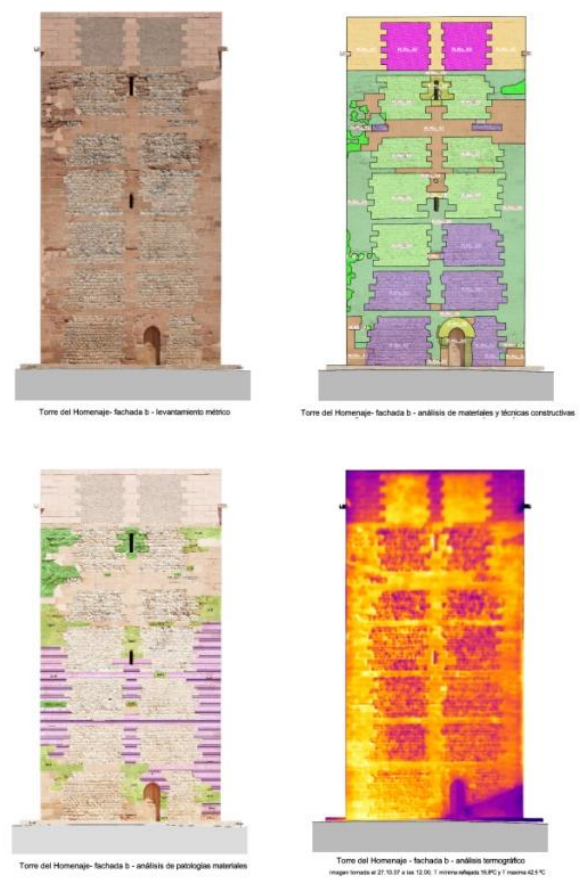

Figure 8. South façade of the Donjon tower. The thermographic façade clearly shows the difference in material (stone ashlars in yellow and orange, and round stones in red and purple) and the diverse thermal response between the upper and the lower part of the tower.

As far as the phenomena of material decay are concerned, thermography offers some new data that seem interesting mainly because they can clearly be detected. Erosion, exfoliation and general stone degradation on the exterior of the buildings is clearly identifiable in the rectified thermophotoplans.

The most disintegrated areas of the stone surface appear clearer, yellowish or even almost white, indicating the level of decay. Thermography also allows the identification of humidity, both capillarity in the lower part of the building and infiltration in the upper part. In some cases, thermography allows the detection of phenomena which are difficult to identify visually, such as leaks or air currents or water passing through the roof, in the case of the Chapel (fig. 9).
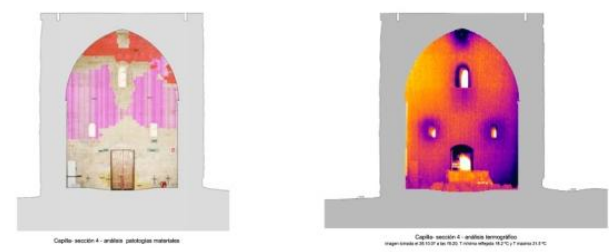

Figure 9. Thermographic plans emphasizing the effects of some pathologies: humidity due to capillarity in the lower part of the Chapel; air passing through the roof of the Chapel

\section{Discussion}

The use of thermography has recently become widespread as it non-destructive, easy to apply, uses portable equipment, etc. In addition, the result of a thermographic study is very clear, while other detection and diagnostic techniques need to define their objectives beforehand to avoid the excessive production of information which often does not produce knowledge but rather, acritical over-information.

Thermography is a well-known technique that can nowadays be easily integrated into multidisciplinary architectural surveys of complex structures, monuments and sites. Although thermographic techniques require an understanding of opto-thermophysical properties as well as patterns for the contraction of materials and buildings, it is worth considering infrared thermography as a basic tool to improve management of cultural heritage not only prior to conservation but over time.

Thermo-mosaics allow users not only to improve spatial resolution but also to present continuous overall metrics with overlaid temperatures. This means that multiple images have to be acquired at the same time to maintain relative conditions. Best results are achieved when maximum thermal contrast exists on the surfaces. As this is not visible, it depends on building conditions, variety of materials, orientation of the feature, among others. Therefore, multi-temporal shots are recommended (Lerma et al., 2012a). In addition, advanced multiband techniques can be selected to process multitemporal infrared imagery and automatically detect alterations or defects (Lerma et al., 2011b). 


\section{Conclusion}

This paper presents a comprehensive review of preliminary studies carried out to understand, characterize and manage an architectural and historic monument as complex as Monzón Castle. Special attention is paid to the importance of thermographic studies as a source of information complementary to elevation plans (including metrics, materials, composition, styles and alterations) and which should not be neglected in conservation and restoration work.

Finally, following the studies of the Castle of Monzón, it can be confirmed that thermography is an efficient technique especially useful for material and pathological studies. In this case, the use of thermography has on the one hand allowed the confirmation of the existence and position of certain pathologies, specifically humidity, while on the other, it clearly emphasizes the differences between materials making it easier to perceive these. This shows its usefulness as a non-destructive technique aiding the study of monuments. It is specially interesting when used together with other detection and survey techniques in a crossed and synoptic analysis, increasing and mutually enriching efficiency. However, the relevance of thermography is best understood when presented in a comprehensive way as thermo-mosaics produced by rectified or orthorectified mosaic images.

\section{References}

Barreira, E., Freitas, V.P., (2007), Evaluation of building materials using infrared thermography. Construction and Building Materials, 21, pp. 218-224.

Cabrelles, M., Galcerá, S., Navarro, S., Lerma, J.L., Akasheh, T., Haddad, N., (2009), Integration of 3D laser scanning, photogrammetry and thermography to record architectural monuments. Proceedings of the $22^{\text {nd }}$ CIPA International Symposium, Kyoto, Japan.

Cañas Guerrero, I., Martin Ocaña, S., González Requena, I., (2005), Thermal-physical aspects of materials used for the construction of rural buildings in Soria (Spain). Construction and Building Materials, 19, pp. 197-211.

Castillón Cortada F., (1989), El Castillo de Monzón, Librería General, Zaragoza.

Delgado Ceamanos, J., (1995), Informe de las actuaciones arqueológicas realizadas en el castillo de Monzón (Huesca) durante 1995. Cuadernos CEHIMO, n. 22, Monzón, pp. 27-28.

Grinzato, E., Vavilov, V., Kauppinen, T., (1998), Quantitative infrared thermography in buildings. Energy and Buildings, 29, pp. 1-9.

Lerma, J. L., Mileto, C., Vegas, F., Cabrelles, M., (2007), Visible and thermal ir documentation of a masonry brickwork building. International Archives of the Photogrammetry, Remote Sensing and Spatial Information Sciences, Athens, Greece, Vol. XXXVI-5/C53, pp. 456-459.

Lerma, J.L., Akasheh, T., Haddad, N., Cabrelles, M., (2011), Multispectral sensors in combination with recording tools for cultural heritage documentation. Change over Time, 1(2), pp. 236-250.

Mileto C., Vegas F., 2006. El edificio y su memoria. Conservación de las huellas del pasado. Património. Estudios, n. 9, pp.72-89.

Mileto C., Vegas F., (2008), Plan Director del Castillo de Monzón, unpublished document.

Mileto C., Vegas F., (2011), Plan Director del Castillo de Monzón, Gobierno de Aragón, CD-ROM.

Möllmann, K.-P., Pinno, F., Vollmer, M., (2007), Influence of wind effects on thermal imaging - Is the wind chill effect relevant? InfraMation 2007 Proceedings, 8, ITC 121A, pp. 21-31, Las Vegas, Nevada.

Nieto, J.J., (2008), Estudio Histórico del Castillo de Monzón. Plan Director del Castillo de Monzón, unpublished document, pp. 18-43. 